\title{
Mobile Subscription, Penetration and Coverage Trends in Kenya's Telecommunication Sector
}

\author{
Omae Malack Oteri \\ Department of Telecommunication and \\ Information Engineering \\ Jomo Kenyatta University of Agriculture \\ \& Technology \\ Nairobi, Kenya
}

\author{
Langat Philip Kibet \\ Department of Telecommunication and \\ Information Engineering \\ Jomo Kenyatta University of Agriculture \\ \& Technology \\ Nairobi, Kenya
}

\author{
Ndung'u Edward N. \\ Department of Telecommunication and \\ Information Engineering \\ Jomo Kenyatta University of Agriculture \\ \& Technology \\ Nairobi, Kenya
}

\begin{abstract}
Communication is the activity of conveying information through the exchange of thoughts, messages, or information, as by speech, visuals, signals, writing, or behavior. In Kenya the mobile subscription, penetration and coverage have been growing since the first mobile operators started operating in 1999. The current mobile operators in Kenya are given by Safaricom Ltd, Airtel Networks Kenya Ltd, Essar Telecom Kenya Ltd and Telkom Kenya Ltd (TKL-Orange).
\end{abstract}

This paper discusses the present condition of the telecommunication sector in Kenya and the trends in subscription, penetration and coverage since 1999 when the first two mobile operators (Safaricom Ltd and Celtel now as Airtel Networks Kenya Ltd) started their operations and later the introduction of two other operators Essar Telecom Kenya Ltd and Telkom Kenya Ltd (Orange brand) in 2008. The paper also tries to find out what is likely to happen in a few years to come and provision of a set of recommendations based on the analysis. The study was based on extensive literature review and secondary data sources mainly from Communication Authority of Kenya (CAK). The data obtained was analyzed using Matlab and Microsoft excel to obtain the relevant graphical representations as given in results and discussions.

Keywords-Communication; Telecommunication; Cellular phone; Civilization; Trends

\section{INTRODUCTION}

Communication has been part and parcel of the human race since time immemorial. Telecommunication is the science of transferring information over long distances by electrical and electromagnetic waves which started with the telegraph, telephone, radio, television, satellites, internet and now commonly mobile communication. It can also be said to represent any process or group of processes that allow the transmission of audio, video information or data over long distance by means of electromagnetic or electrical signals. The invention of a practical telegraph in the late 1830s and the telephone in 1876 brought humanity into the era of electrical telecommunications. After over 100 years of triumph, public telegraphy left the communications market. But telex took over and evolved into massively popular forms such as SMS and email, while telephony remains the most widely used means of communication in the world today. Over the past century or so, communications technologies have advanced from manual to automatic switching and from analog to digital communications, alongside many other major technological revolutions.

However, the greatest changes in consumer experience did not occur until mobile phone and the Internet came out and became common elements of life, and which continue to generate even larger changes [1].

In our study we shall look at it as the transfer of information from one location to the other using mobile phone or cellular phone.

In earlier times a "Telephone" was a symbol of status. It was quite a difficult and lengthy process for one to have a telephone connection at his/her home. This time provided by only telecom Kenya up to 1999 when we had the entrance of mobile operators Safaricom and Celtel. In case of an emergency when someone needed to call abroad there was so much harassment in getting a line or if you were lucky to get it, was not clear, distance call rate was so high that sometimes poor people could not afford. Even locally for those who were not lucky enough to get a line had to make long queues behind a telephone booth (located at long distances from one's home) to make a call. But now the situation is totally changed in that technology is available which can avail the information within a very short time thanks to mobile phones. This has drastically changed our lives by making it easy for us as everyone can attest to this. Employment opportunities have increased whereby most graduates get placed in formal employment in the telecommunication sector which can take graduates from various fields.

For instance telecommunication, information technology, human resource and other graduates can easily fit into this sector. The Government has also greatly benefited from the revenues from this sector taking an example of companies like Safaricom contributing up to a tune of several billions in a year. Also information technology has got a big boost by mobile phone technology growth more so in the mobile application software development section. These rapid changes have been made possible with the mobile technology growth. From the information found in the yearly reports from Communications Authority of Kenya (CAK) reveals that mobile phone subscription in Kenya reached the 32.2 million subscriptions by June 2014 [2]. The mobile penetration has not been left behind in which case it has also been increasing from 1999 to march 2014 where it hit a high of $78 \%$. 


\section{A. Statement of the problem}

Information communication technology is an important sector in any country where it plays a very important role in a nation's economy. Researchers have not looked into the study of the trends of mobile subscription and penetration over the period from 1999 to 2013 . This research is intended to have a detailed study on the trends of this industry in Kenya and maybe world over. This can help the telecommunication industry understand the trends and what is likely to happen in the near future so that they can give it a strategic response.

The telecommunications industry in Kenya has been undergoing rapid changes. The Communications Authority of Kenya has in the past 15 years licensed four mobile operators (Safaricom, Airtel and Essar (Yu); all of which are global operators) and several internet service providers like Wananchi and Jamii Telkom. Clearly, competition in this sector has greatly intensified in both the voice and data service provision.

\section{B. Research objectives}

The broad objective of the paper is to make an extensive study on the trends experienced in the telecommunication sector in Kenya. The specific objectives are:

- Determine the mobile subscription trend in Kenya.

- Determine the mobile penetration trend in Kenya.

- Analyze the above two.

- To find out the determinants that affects the expansion (growth) of the sector.

\section{Importance of the study}

The study would be valuable to several stakeholders for the following reasons:

1) Enable the telecommunication companies to know the trends in mobile subscription in Kenya.

2) Help companies to make informed future plans.

3) Enable the telecommunication companies to know the trends in mobile penetration in Kenya.

4) Telecommunication companies can use the findings to develop appropriate policies and strategic responses to the challenges as result of the rate of subscription and penetration.

5) Enable CAK to give proper guidance to the mobile phone operators.

The study would also provide a source of inspiration to a researcher for self-professional development and enrichment.

\section{LITERATURE REVIEW}

\section{A. Telecommunication sector in Kenya}

Up to date there are four mobile operators in our country namely Safaricom Ltd, Airtel Networks Kenya Ltd, Essar Telecom Kenya Ltd and Telkom Kenya Ltd (Orange). According to the mobile subscription and profitability Safaricom Ltd is in the top position among the four operators [2]. The other companies have lower market shares as shown in the study but their main companies are the world's famous and big organizations like Airtel has very high subscription in most Asian countries including India (highest with 183.61 million subscribers as of November 2012) and Bangladesh (third with 5.1 million subscribers as of June 2011) [3]. They have invested a lot and also have more plans for investment having in mind that their key objective is to earn profits. By the end of the third quarter of the 2013/14 financial year (June. 14), there were a total of 32.2 million subscriptions in the mobile telephony market segment up from 31.8 million posted in the previous quarter. This represents an increase of 5.6 percent during the period. Mobile penetration grew to reach 79 percent from 78 recorded at the close of the previous quarter.

\section{B. Mobile subscription}

Mobile cellular telephone subscriptions are subscriptions to a public mobile telephone service using cellular technology, which provide access to the public switched telephone network. Post-paid and prepaid subscriptions are included [4]. The number of mobile subscribers usually gives an indication of how vibrant the telecommunication sector of a country is. It also shows the rate of growth of the sector. It can help many companies determine their stage of growth and respond strategically to the different challenges that come with each stage. The market share for each player in this field can also be determined using this very important indicator.

\section{Mobile penetration}

Mobile phone penetration rate is a term generally used to describe the number of active mobile phone numbers (usually as a percentage) within a specific population [5]. This value can go beyond $100 \%$ due the fact that one person can have more than one SIM-card. This can be noted from countries like Qatar which has 170\% [6] and most of Europe with 128\% [7].

\section{Mobile coverage}

In telecommunications, the coverage of a radio station is the geographic area where the station can communicate. Broadcasters and telecommunications companies frequently produce coverage maps to indicate to users the station's intended service area. Coverage depends on several factors, such as orography (i.e. mountains) and buildings, technology, radio frequency, transmitted power and distance from the station. Some frequencies provide better regional coverage, while other frequencies penetrate better through obstacles, such as buildings in cities.

The ability of a mobile phone to connect to a base station depends on the strength of the signal. That may be boosted by higher power transmissions, better antennae and taller antenna masts. Signals will also need to be boosted to pass through buildings, which is a particular problem designing networks for large metropolitan areas with modern skyscrapers. Signals also do not travel deep underground, so specialized transmission solutions are used to deliver mobile phone coverage into areas such as underground parking garages and subway trains. This is the same case with indoor coverage [8]. This is also an important parameter in showing the number of people who are likely to receive a signal depending on their location. This parameter can go up to a maximum of $100 \%$ since it deals with the area occupied by a country. 


\section{RESEARCH METHODOLOGY}

\section{A. Research design and data collection}

This study basically covers a period of 13 years starting from 1999 to 2013. An attempt has also been made to include the latest information whenever available.

Much of the information for this research was obtained from secondary sources i.e. the internet e-journals, e-books and websites. This was done by collecting data from the reports of the Communications Commission of Kenya (CAK), via the internet.

Annual reports of different telecom companies, articles published in newspapers, conference papers and seminars proceedings were also carefully studied to procure the needed information. The report only presents simple frequency and quantitative tables. Various statistical tools and techniques have been applied for the analysis and interpretation of data.

\section{B. Data analysis}

For this study, the content analysis technique was employed to analyze the data. Matlab and Microsoft Excel Spread Sheet, with the associated trend analysis and graphical representation techniques were used to analyze quantitative data. The full report on the key findings of this study by the researcher is presented in section below.

\section{FINDINGS AND DISCUSSIONS}

\section{A. Introduction}

This section deals with analysis and discussion of the research findings. Data was collected from the CAK website in which case the mobile subscription and penetration are analyzed. Following is a report on the key findings of this study by the researcher.

\section{B. Market share analysis of telecom sector in Kenya:}

TABLE I. TOTAL MoBILE SUBSCRIPTIONS

\begin{tabular}{|l|l|l|l|}
\hline $\begin{array}{l}\text { Subscription } \\
\text { Type }\end{array}$ & June-14 & March-14 & $\begin{array}{l}\text { Quarterly } \\
\text { Variation (\%) }\end{array}$ \\
\hline $\begin{array}{l}\text { Prepaid } \\
\text { Subscriptions }\end{array}$ & $31,580,696$ & $31,222,434$ & 1.1 \\
\hline $\begin{array}{l}\text { Post-Paid } \\
\text { Subscriptions }\end{array}$ & 665,697 & 607,569 & 9.5 \\
\hline $\begin{array}{l}\text { Total Mobile } \\
\text { Subscriptions }\end{array}$ & $\mathbf{3 2 , 2 4 6 , 3 9 3}$ & $\mathbf{3 1 , 8 3 0 , 0 0 3}$ & $\mathbf{1 . 3}$ \\
\hline
\end{tabular}

Mobile subscription by June 2014

By June 2014 the total number of mobile subscriptions was recorded as 32.2 million up from 31.8 million posted in the previous quarter (March the same year). This represents an increase of 5.6 percent during the period. The continued growth in mobile subscriptions indicates that there is still opportunity for growth in the mobile telephony services. However, the rate of growth in the subscriber base is flattening as the sector progressively tends towards maturity. Consistent, attractive promotions and special offers coupled with competitive retail tariffs could have contributed to the increase in subscriptions during this period. The prepaid subscriptions grew by 1.1 percent during the period compared to 9.5 percent growth recorded in post-paid subscriptions. Even though the growth rate for post-paid subscriptions was more than that for pre-paid, the ratio of prepaid subscriptions continued to dominate and represented 98.0 percent of the total mobile subscriptions. This is consistent with the trends in developing countries where prepaid service is preferred due to the ease and convenience of subscription compared to postpaid which has requirements that are not within the reach of the majority of the population. The reduction of the value of prepaid calling cards to as low as KES 5.00 has made prepaid services a choice for most low income subscribers. Besides the availability of low value cards one can now easily access credit through money transfer methods like M-pesa and advance credit like Okoa Jahazi.

The growth of mobile subscriptions is shown in Table I.

Among the operators at the end of June 2014, Safaricom had the highest subscriber with $21,928,450$, Airtel is in the second positions with the total subscriber base of 5,068,765, Essar Telecom Kenya Limited with 2,563,810 and then Telkom Kenya Limited (Orange) with 2,685,368 subscribers which stands as the fourth largest mobile phone operator in Kenya.

During the period under review, three mobile operators recorded positive gains in subscriptions. Telkom Kenya Limited (Orange) recorded the highest gains in new subscriptions of 231,470 , representing a growth of 9.4 percent compared to the previous quarter. Safaricom Limited gained 361,062 (1.7\% growth) new subscribers while Airtel Networks

Kenya Limited lost 130,005 (-3.5 \% growth). Essar Telecom Kenya Limited on the other hand gained 511,526 subscriptions, representing 0.2 percent increase from the previous quarter. The following table shows the number of mobile subscribers in Kenya as of June 2014 [2].

TABLE II. MOBILE SUBSCRIPTIONS PER OPERATOR

\begin{tabular}{|l|l|l|l|}
\hline \multirow{2}{*}{ Name of operator } & June-14 & \multicolumn{3}{|l|}{} \\
\cline { 2 - 4 } & Pre-paid & $\begin{array}{l}\text { Post- } \\
\text { paid }\end{array}$ & Total \\
\hline Safaricom Limited & $21,405,667$ & 522,783 & $21,928,450$ \\
\hline $\begin{array}{l}\text { Airtel Networks } \\
\text { Kenya Limited }\end{array}$ & $4,930,774$ & 137,991 & $5,068,765$ \\
\hline $\begin{array}{l}\text { Essar Telecom } \\
\text { Kenya Limited }\end{array}$ & $2,562,339$ & 1,471 & $2,563,810$ \\
\hline $\begin{array}{l}\text { Telkom Kenya } \\
\text { Limited (Orange) }\end{array}$ & $2,681,916$ & 3,452 & $2,685,368$ \\
\hline Total & $\mathbf{3 1 , 5 8 0 , 6 9 6}$ & $\mathbf{6 6 5 , 6 9 7}$ & $\mathbf{3 2 , 2 4 6 , 3 9 3}$ \\
\hline
\end{tabular}

\begin{tabular}{|l|l|l|l|}
\hline March-14 & Post-Paid & Total & $\begin{array}{l}\text { Quarterly } \\
\text { Variation } \\
(\%)\end{array}$ \\
\hline Pre-paid & & & 1.7 \\
\hline $5,121,094,414$ & 472,974 & $21,567,388$ & -3.5 \\
\hline $2,556,110$ & 130,005 & $5,251,087$ & 0.2 \\
\hline $2,450,828$ & 1,520 & $2,557,630$ & 9.4 \\
\hline $\mathbf{3 1 , 2 2 2 , 4 3 4}$ & 3,070 & $2,453,898$ & 1.3 \\
\hline
\end{tabular}




\section{PERCENTANGE SUBSCRIPTION MARKET SHARE PER OPERATOR}

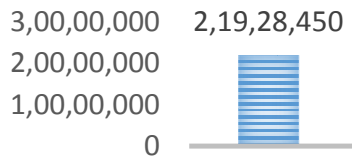

Fig. 1. Percentage market share per operator as of June 2014

The level of market share measured by subscription is still dominated by Safaricom. Safaricom Ltd market share by subscription was 68 percent during the period under review. Telkom's (Orange) market share percentage points stands at 8 percent at the end of the quarter.

Airtel Networks Kenya Limited's market share is given by 16 percent while that of Essar Telecom's is at 8 percent. The market share by subscription by operator is shown in Figure 1.

Mobile subscription from 1999 to 2013

The table below summarizes the key findings on the mobile subscription from the year 1999 to 2013. The data provided is on yearly basis taking subscription as of December each year.

Since the Communication Authority of Kenya (CAK) then CCK issued the two mobile licenses in 2000 (Safaricom and Celtel now Airtel), the mobile telecommunication continued to be popular with consumers. For the first five years the sub sector registered over $60 \%$ annual growth with over $16,233,833$ subscribers at the end of December 2008. In 2005 the growth rate shot up to $106 \%$ but then started declining from 2006 to December 2011 where it was $12 \%$. The sudden increase could be attributed by the fact that around this time there were so many promotions. The difference between the subscribers in 2008 and 2007 was close to 4million because of the introduction of the other two mobile operators TKLOrange brand and Essar Telcom Kenya limited in 2008.

TABLE III. MOBILE SUBSCRIPTIONS, 1999 To 2013

\begin{tabular}{|l|l|l|l|l|}
\hline Year & $\mathbf{1 9 9 9}$ & $\mathbf{2 0 0 0}$ & $\mathbf{2 0 0 1}$ & $\mathbf{2 0 0 2}$ \\
\hline $\begin{array}{l}\text { Number of } \\
\text { mobile } \\
\text { subscribers }\end{array}$ & 15,000 & 114,000 & 585,131 & $1,325,222$ \\
\hline $\mathbf{2 0 0 3}$ & $\mathbf{2 0 0 4}$ & $\mathbf{2 0 0 5}$ & $\mathbf{2 0 0 6}$ & $\mathbf{2 0 0 7}$ \\
\hline $1,590,785$ & $2,546,157$ & $5,263,676$ & $7,340,317$ & $11,440,077$ \\
\hline $\mathbf{2 0 0 8}$ & $\mathbf{2 0 0 9}$ & $\mathbf{2 0 1 0}$ & $\mathbf{2 0 1 1}$ & $\mathbf{2 0 1 2}$ \\
\hline $16,233,833$ & $19,364,559$ & $24,968,891$ & $28,080,771$ & $30,731,754$ \\
\hline $\mathbf{2 0 1 3}$ & & & & \\
\hline $31,830,003$ & & & & \\
\hline
\end{tabular}

The highest difference was between 2010 and 2009 attributed most probably by the fact that the Orange grew with a higher rate and also the competition of the new entrants with the already existing mobile operators. From 2012 to 2013 increase was only 3.6 percent mostly as a result of sim card registration in Kenya where deadline was 2013 December.
Another reason is due to Mobile tariffs reducing significantly over the period registering an average of KES 2.65 for on-net calls per minute from KES 4.78 per minute in the previous period and KES 2.5 for post-paid subscribers at the end of the period under review.

This represents 33.4 per cent reduction on pre-paid tariffs and 55.5 per cent on post-paid tariffs from the previous period.

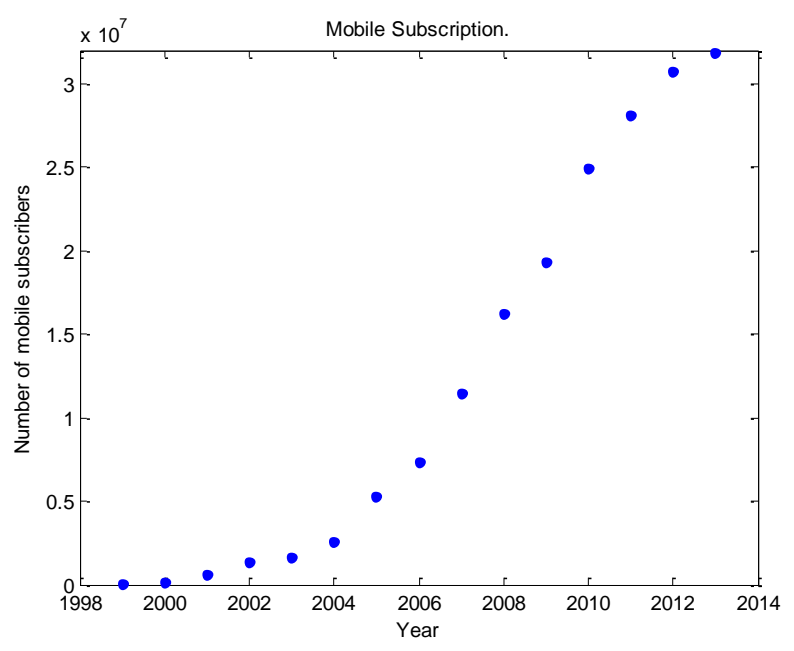

Fig. 2. Mobile subscription from 1999 to 2013

The tariff decline is attributed to an interconnection determination by the Commission during the period that saw mobile termination rates reduced to KES 2.21 from KES 4.42 coupled with increased competition among operators in the mobile market which followed the acquisition of Zain by Bharti Airtel whose business strategy seemed to target the mass market. The figure below is a graphical representation of the number of subscribers against the years.

TABLE IV. MOBILE SUbSCRIPTIONS GROWTH RATE

\begin{tabular}{|l|l|l|l|l|l|l|l|}
\hline Year & $\mathbf{1 9 9 9}$ & $\mathbf{2 0 0 0}$ & $\mathbf{2 0 0 1}$ & $\mathbf{2 0 0 2}$ & $\mathbf{2 0 0 3}$ & $\mathbf{2 0 0 4}$ & $\mathbf{2 0 0 5}$ \\
\hline $\begin{array}{l}\text { Mobile } \\
\begin{array}{l}\text { Subscri } \\
\text { ptions } \\
\text { growth } \\
\text { rate }\end{array}\end{array}$ & $\begin{array}{l}660 \\
\%\end{array}$ & $\begin{array}{l}413 \\
\%\end{array}$ & $\begin{array}{l}126 \\
\%\end{array}$ & $20 \%$ & $60 \%$ & $\begin{array}{l}106 \\
\%\end{array}$ \\
\hline $\mathbf{2 0 0 6}$ & $\mathbf{2 0 0 7}$ & $\mathbf{2 0 0 8}$ & $\mathbf{2 0 0 9}$ & $\mathbf{2 0 1 0}$ & $\mathbf{2 0 1 1}$ & $\mathbf{2 0 1 2}$ & $\mathbf{2 0 1 3}$ \\
\hline $39 \%$ & $56 \%$ & $42 \%$ & $19 \%$ & $29 \%$ & $12 \%$ & $8 \%$ & $4 \%$ \\
\hline
\end{tabular}

From the graph we can be able to see that at the initial stages the growth was not as high as the later stages. Between 2004 and 2011 the growth rate was very high this is due to still there were several people in the country without mobile phone considering the total population of about 40 million. From 2011 onwards the subscription seems to start leveling. The leveling could be due to expected market maturity. Because of this mobile operators should introduce value added services to stay afloat. The services include additions to money transfer and different other mobile technologies (m-technologies). We can conclude that the graphical changes seem to follow a natural trend of exponential growth. 
This is because at the initial stages there is a slow growth, the middle is characterized by high growth with steep gradient and towards the end the growth starts to flatten.

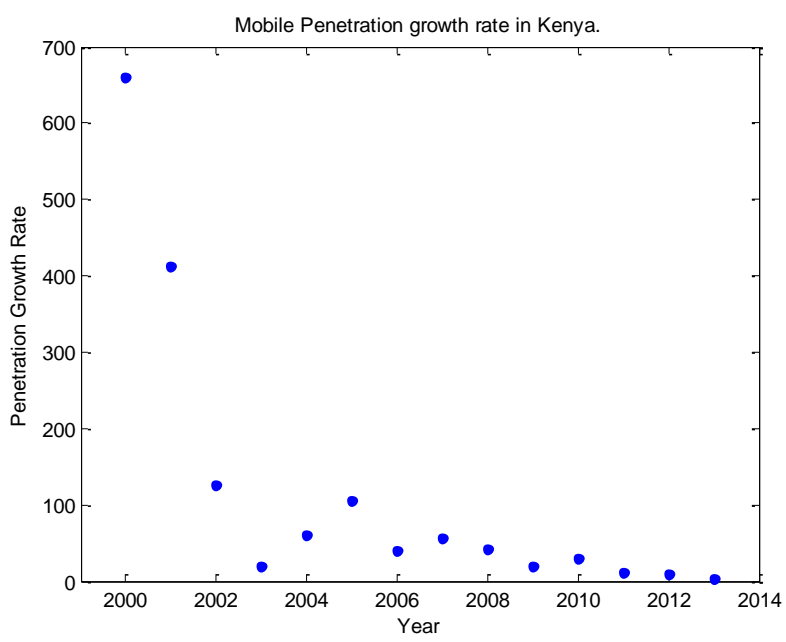

Fig. 3. Mobile subscriptions yearly growth rate

The figure above is a graphical representation of the penetration growth rate against the years. The graph shows that the period between 1999 and 2002 was high but decreasing by the year. This could be attributed by the fact that during this period the business was at its initial stages of growth. From 2003 to 2005 the growth rate increased. From 2005 to 2012 there were slight variations probably due market maturity in which most of the new subscribers are the youth.

\section{Mobile penetration}

Over the last thirteen years mobile penetration has registered an exponential growth from 0.053 in 1999 to 80 in December 2013. The increase in mobile penetration can be attributed to a number of factors. First, the reduction in the value of calling cards from the lowest of Kshs 250 in 1999 to Kshs 5 by September 2012 which has made calling cards affordable to low income earners thus stimulating this positive trend. Secondly, the average costs of making calls has declined from Kshs 27 to Kshs 1 to the same network. This has led to increased uptake of mobile phones as costs of calls become affordable thus increasing subscription rates and penetration. International call charges, on the other hand, have also changed over the period because of the use of VOIP technology. Third, even as the mobile operators adjust their tariffs, the mobile coverage has also increased with services now available to a higher population. The increase in mobile penetration can also be attributed to increase in the number of mobile operators from two in 1999 to four in 2008, increased mobile coverage.

The table above shows the mobile penetration in \% in Kenya from 1999 to 2013. The mobile penetration per operator as of December 2013[2]
TABLE V. MOBILE PENETRATION

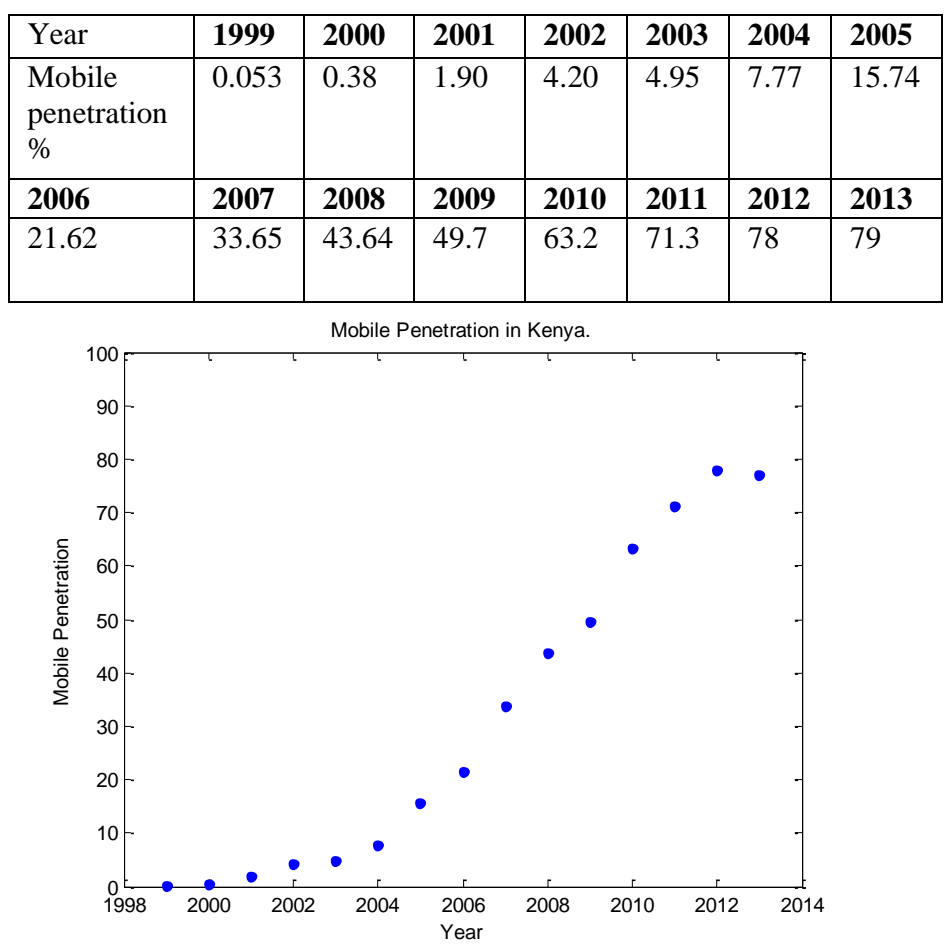

Fig. 4. Mobile penetration in Kenya

The graphical representation above is for mobile penetration against the years from 1999 to 2013. It can be noted that the rate is very low at initial stages being the time when the first two mobile operators were licensed in Kenya. This trend continued up to 2004 when the rate started growing. The growth saw high mobile penetration rate from this time to 2013. This could be attributed by the fact that there were high levels of competition between the first two operators which was even higher after the entrance of two other new operators Orange and Essar. In 2013 it declined probably because of the government policy that required that all mobile phone users and their sim cards be registered by December 2013 where the unregistered cases were to be locked out.

\section{Mobile coverage}

The current level of competition in the country has witnessed a network expansion by the four operators to levels that have surpassed their license conditions. This could be attributed to entry of the two mobile operators within the period of December 2008 which may have compelled the existing operators to expand their network coverage in order to solidify their market positions.

Establishment of new sites in areas hitherto considered uneconomical, has in effect increased the level of population coverage including some rural areas. 
However, as is the case in most developing countries, this coverage is concentrated in areas with high population densities and promising economic potential especially in urban areas and along major highways. With a national coverage of about $77 \%$ of the population, the mobile industry invariably covers over 31 million people in the country. However, the $38 \%$ geographic coverage implies that many parts of the country are not covered especially the arid and semi-arid areas. The challenge is how to make these services affordable to the wider population and to encourage investment in high cost areas.

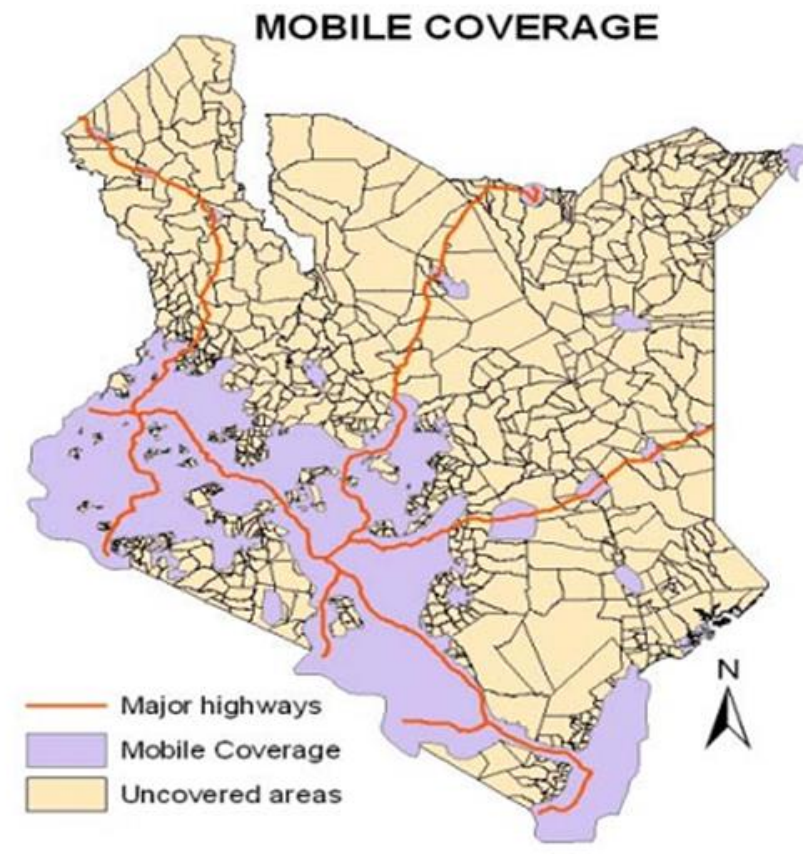

Fig. 5. A map of mobile coverage

As shown in the figure above the covered areas count for a mere $38 \%$ by June 2012 while the rest of the country remains uncovered.

\section{SUMMARY, CONCLUSIONS AND RECOMMENDATIONS}

\section{A. Summary}

The objectives of this study were to analyze the mobile subscription and penetration trends in the telecommunication industry in Kenya. The researcher found out that subscription and penetration rate have been growing since the first two companies Safaricom and Celtel (now Airtel) were licensed. By June 2014 the total number of mobile subscriptions was recorded as 32.2 million up from 15 thousand posted in 1999. Both mobile penetration and coverage have also been steadily growing.

\section{B. Conclusion}

There has been significant growth in telecommunication sector particularly in the use of mobile telephony. Competition among the operators, unification of the licenses and the application of new technologies in mobile market segment has witnessed diversification of services by the operators, reduced tariff rates and increased affordability of communication services by a large population. This is further seen as a movement towards closing the digital divide.

The telecommunication landscape in Kenya has continued to be shaped by technological developments arising out of convergence and the new market structure. The subsequent shifts in consumer needs and expectations has compelled aggressive network roll out and infrastructure upgrades using technologies that support high capacity services. Increased competition among the operators has also contributed to the high level of product and service innovations as a means of customer acquisition and customer retention. This is as witnessed in the increase in subscriber base by the fixed network operator.

The outlook of the communication sector in Kenya continues to be strong, and growth will be achieved through gaining new customers, offering new services, and in general capitalizing on the growing role of telecommunications in people's everyday lives. The mobile sector in the country continues to grow increasingly competitive. This is shown with the steady growth in subscriptions.

Increased competition in the mobile sector has resulted in steady growth of this market segment as the services become more affordable. Consequently, the number of mobile subscriptions as well as mobile coverage patterns has continued to demonstrate a positive growth over the period. This trend is likely to continue in future as operators continue employing innovative ways of creating market niche and retaining customers.

The mobile data and internet market experienced an exponential growth on the number of internet users. This is a step forward towards bridging the digital divide in the country with mobile phones being the instrumental platform to accessing internet. The development has greatly contributed in facilitating ease of doing business for small and medium enterprises as operators offer tailor made services for this market at increasingly affordable costs. In addition, internet connectivity has been enhanced by the operationalization of the submarine cables which has led to a reduction to the cost of bandwidth. This in effect has spurred growth in the data market as is witnessed with increased utilization of e-services. Some notable initiatives include the development in e-transactions such as the Mobipay that enables customers buy and pay for goods through the internet, the introduction of e-ticketing services by some bus companies. There is opportunity for further growth with the expected connectivity through an additional cable in the future.

With competitive pressure likely to remain intense among the four service providers, growth in subscriptions is expected to continue to rise further even though it is headed for maturity. This growth is expected to increase as more and more people especially the youth continue to join the social networks like face book, twitters and blogs.

The Information communication technology (ICT) sector continues to experience growth as witnessed in the increase in 
subscriptions. The sector is largely driven by the mobile telephony, which continues to dominate the sector. Considering this trend, the coming periods are likely to continue recording growth as operators devise innovative products and services expected to entice subscribers and thus propel this sector even further. The steady growth in the mobile industry sector as recorded by increased subscriptions and traffic is expected to continue with constant technological innovations and continued demand for cellular services. The influential factors in the evolution of mobile services are but not limited to the following; rapid growth in the internet, increasingly data hungry applications, data overtakes voice traffic, users want mobility, prices for voice decrease, huge potential for mobile internet, bleak future for voice revenues and access needed to desktop applications when mobile. Even as operators offer attractive promotions and special offers, this will undoubtedly bring about increased subscriptions and growth in traffic during the coming periods. The mobile money transfer service continues to gain popularity due to its convenience and effectiveness. Owing to its growth pattern, operators will be keen to extend the service to the un-banked population and this is expected to expand this service further.

The ease of subscription coupled by the ease of accessing the service through the mobile phone has enhanced growth in this market segment. Moreover, there is still unexploited capacity and potential in this market segment. Consideration for projects geared towards optimal utilization of this capacity could be valuable as this will ultimately stimulate further growth in this market segment.

\section{Recommendations}

In the light of the foregoing findings by the researcher, Telecommunication companies should keenly implement the following:

- Concentrate their energies in value added services in order lock in the already existing subscribers and also attract new subscription since the market is headed for saturation.

- Look for ways of improving mobile penetration and coverage while balancing on their returns.

- Research on the different ways of increasing quality of service to significantly new competitive levels.

\section{Limitations of the study}

Major limitation of the study is lack of available information and previous workings on the topic. There are not enough supportive articles to make an extensive literature review. Also, most of the secondary data obtained and used were scattered. Kenya being a dual-SIM market (where over half the subscribers own three or four lines), counting each SIM card bought could be misleading as well as the fact that the data obtained includes unregistered SIM-cards.

\section{E. Areas of further study}

Future research should include forecasting the future of telecommunications firms in Kenya using different methods. Another area of study would be to look at the impact of market maturity on the competitiveness of Kenyan telecommunications companies.

\section{F. Future outlook}

The future outlook of the telecommunication is positive as the Commission did the implementation of the Kenya Communications Amendment Act 2008. Telecommunication infrastructure will have a major boost with the completion of the National Optic Fibre Backbone Infrastructure. This key infrastructure is expected to increase bandwidth capacity, in most parts of the country which should have a positive impact on internet diffusion and mobile coverage in rural and remote areas. With the recent focus on local content by data service providers' internet usage in the country is expected to rise. Because of the expected market maturity the telecommunication companies should invest more in value added services and improvement of quality of service.

\section{REFERENCES}

[1] Hequan, W. (2009). Telecommunications: challenges \& transformation [Technology Leaders Forum]. Communications Magazine, IEEE, 47(1), 10-13.

[2] CAK (2008-2014). Quarterly Sector Statistics Reports. (Online) Available: http://www.cck.go.ke/resc/statcs.html

[3] R. Jai Krishna and Prasanta Sahu (2010-01-12). "Bharti Airtel to Buy Warid Telecom for \$300 Million - WSJ.com"

[4] The World Bank Group. (Online) Available: http://data.worldbank.org/indicator/IT.CEL.SETS.P2

[5] Pearson press financial times, (online) available: http://www.ftpress.com/articles/article.aspx? p=463943\&seqNum=5

[6] Qatar, (online) available: http://www.ameinfo.com/qatar-mobilepenetration-reached-170-q3-330556

[7] (Online) available: http://www.parseco.com/worlds-mobile-penetration/

[8] (Online) available: http://www.askcomreg.ie/mobile/ coverage.44.LE.asp 